\title{
Alopesilerde trikoskopi
}

\section{Trichoscopy in alopecias}

\section{A. Tülin Gülec}

Bașkent Üniversitesi Tıp Fakültesi, Deri ve Zührevi Hastalıklar Anabilim Dalı, Ankara, Türkiye

\section{Özet}

Birbirinden farklı birçok hastalık grubunu içeren alopesiler, en sık görülen deri hastalıklarından biridir. Detaylı hastalık öyküsü ve iyi bir klinik muayene çoğu zaman doğru tanı koymak için yeterli olabilmektedir. Skatrisyel alopesiler gibi durumlarda ise saçlı deriden biyopsi almak gerekebilmektedir. Öte yandan, histopatolojik bulgular her zaman tanı koydurucu değildir. Bu nedenle, tanı zorluğu yaşanan alopesilerde klinisyene yardımcı olacak yeni tanı yöntemlerine ihtiyaç vardır. Trikoskopi olarak da adlandıılan saçı deri dermoskopisi, saçı deri ve saç hastalıklarııı tanısında ümit vaat eden yeni bir yöntemdir. Son yıllarda, alopesilerin trikoskopik bulguları hakkında birçok çalışma yayınlanmıştır. Bu derlemede, belli başlı trikoskopik bulgular gözden geçirilerek, normal saçlı deri ile skar bırakan ve bırakmayan alopesilerde görülen bulgular üzerinde durulmuştur. (Türkderm 2014; 48: Özel Sayı 1: 19-23)

Anahtar Kelimeler: Alopesi, dermoskopi, saç, saçlı deri, trikoskopi

\section{Summary}

Scalp alopecias reflecting a broad spectrum of heterogeneous diseases are among the most common dermatologic disorders. A careful history and a thorough clinical examination are usually adequate to establish the correct diagnosis. In some cases, e.g. cicatricial alopecias, a scalp biopsy may be necessary. However, the histopathologic features are not always diagnostic. Consequently, new helpful diagnostic methods are required for the alopecias with diagnostic difficulties. Scalp dermatoscopy, also named as trichoscopy, is a promising way to facilitate the diagnosis of scalp and hair disorders. Numerous reports have been published regarding the trichoscopic features of several alopecias in recent years. In this article, an overview about the main trichoscopic structures and patterns in addition to the findings observed in normal scalp and alopecias covering nonscarring and primary scarring ones, is discussed. (Turkderm 2014; 48: Suppl 1: 19-23)

Key Words: Alopecia, dermoscopy, hair, scalp, trichoscopy

\section{Giriş}

En sık görülen deri hastalıklarından biri olan alopesilerin tanısı çoğunlukla ayrıntılı anamnez, klinik muayene ve hafif çekme testi ile trikogram gibi yardımcı tetkiklerle konur. Öte yandan, primer skatrisyel alopesilerde (PSA) ve jeneralize saç dökülmesine yol açabilen alopesi areata (AA) incognito, kronik telogen effluvium (TE) ile androgenetik alopesinin (AGA) birbirinden ayırt edilmesi gereken durumlarda invazif bir yöntem olan saçlı deri biyopsisine gerek duyulur. Bununla birlikte, histopatolojik bulgular her zaman tanı koydurucu olmayabilir¹. Bu nedenle, tanı zorluğu yaşanan alopesilerde klinisyene yardımc olacak yeni yöntemlere ihtiyaç vardır. Son yıllarda başta alopesiler olmak üzere çeşitli saçlı deri hastalıklarının tanısında "trikoskopi" olarak da adlandırılan dermatoskopik muayene başarıyla kullanılmaya başlanmıştır 1-10.

Trikoskopik muayenede öncellikle videodermatoskop kullanılması tercih edilmiştir çünkü yüksek çözünürlükte, 201000 kat büyütülebilen görüntüler kolaylıkla bilgisayarda depolanabilmektedir1,3-9. Öte yandan, taşınabilir olmaması ve pahalı olması nedeniyle videodermatoskop her klinikte bulunmamaktadır. On kat büyütme sağlayan el dermatoskopu ise dijital kameraya bağlanınca 30 kat büyütebilmektedir ama

Yazışma Adresi/Address for Correspondence: Dr. A. Tülin Güleç, Başkent Üniversitesi Tıp Fakültesi, Deri ve Zührevi Hastalıklar Anabilim Dalı, Ankara, Türkiye Tel.: +90 31221229 12/260-270 E-posta: tulinogulec@hotmail.com

Türkderm-Deri Hastalıkları ve Frengi Arșivi Dergisi, Galenos Yayınevi tarafından basılmıștır.

Turkderm-Archives of the Turkish Dermatology and Venerology, published by Galenos Publishing. 
fotoğrafları çekip, bilgisayara aktarmak daha zahmetli bir iştir. Ancak, cepte bile taşınabilen bu alet, göreceli olarak çok daha ucuzdur ve alopesilerin tanısında videodermatoskop kadar başarılı olduğu gösterilmiştir10-15.

\section{Trikoskopik bulgular}

\section{Foliküler bulgular:}

\section{Kıl Gövdeleri}

Kırık saçlar: Saçların deriden çıktıktan sonra birkaç milimetre uzunlukta kırılmasıyla oluşur. En sık $A A^{\prime}$ da görülse de AGA, trikotilomani ve PSA'da da görülebilir 16 .

Incelen saçlar: Proksimal çapları distaldekinden daha ince olan saçlara denir. iki şekilde olabilirler; "Ünlem işareti” saçlar farklı uzunlukta kırılmış olan saçlardır. "Bükülebilir saçlar" denilenlerin boyu ise normal saçlarla aynıdır ama proksimal kısımları incedir. İncelen saçlar peribulbar lenfosit inflitrasyonuna bağlı olarak sadece $A A^{\prime}$ da görülür ${ }^{14}$.

Kısa vellüs saçlar: Uzunluğu 10 mm'yi geçmeyen ince saçlardır. Alopesi areata, AGA, TE ve normal saçlı deride görülebilir ${ }^{14}$.

Saç çapı farklılıkları (Anizotrikozis): Terminal saçların minyatürizasyon sonucu vellüse dönüşmesiyle oluşur. Minyatürleşme her kıl folikülünü aynı anda etkilemediği için değişik çaplardaki vellüsler ve terminal kıllar bir arada görülür. Alopesi areata, TE ve PSA'da değişen oranlarda görülse de, AGA'lı hastaların hepsinde görülür. Saçların \%20'sinden fazlasında saç çapı farklılığı görülmesi AGA için tanı koydurucu bir bulgudur1,15.

Tutam saçlar: Normal saçlı deride 2-4'lü tutamlar görülürken, aynı kıl folikülünden 5 'den fazla saç çıkmasıyla karakterizedir. Komşu foliküllerin harabiyeti sonucunda dış kök kılıflarının birleşmesi nedeniyle ortaya çıkar. Disekkan selülitte (DS) görülebilirse de, folikülitis dekalvans (FD) ve akne keloidalis nucha için karaktersitik bir bulgudur16,17.

\section{Noktalar:}

Sarı noktalar: Dilate olmuş foliküler infundibulumda sebum ve/veya keratin birikmesiyle ortaya çıkar. Sıklıkla ortasında kıl bulunmasa da, bazen vellüs ya da distrofik kıllar görülebilir1,5. En sık ve yoğun olarak AA'da görülür ama diskoid lupus eritematozus (DLE), DS, AGA ve normal saçlı deride de görülebilir1,9,18. Özellikle ani başlayan diffüz alopesilerde AA incognitonun TE'den ayırt edilmesinde çok faydalıdır; saçı deride yaygın olarak sarı noktalar görülmesi AA tanısı koydurur. Sarı noktalar, DLE'de büyük çaplı, koyu sarı renkte görülür. Disekkan selülitte ise "sabun köpüğü" olarak adlandırılan 3 boyutlu sarı noktalar izlenir 18 .

Siyah noktalar (kadaverize saçlar): Saçların deriden çıkmadan önce kırllip kopması sonucunda oluşur1,14. En sık $A A^{\prime}$ da görülse de trikotilomani, DS, tinea kapitis ve anagen effluviumda $(A E)$ da görülebilir 18,19. Siyah noktalar $A A^{\prime}$ da hastalık aktivitesinin göstergesidir; çok sayıda siyah nokta görülmesi, negatif prognostik bir faktördür ${ }^{14}$.

Beyaz noktalar: Peripilar yerleşen beyaz dairelerdir. İki farklı çeşiti vardır. Illki, folikül harabiyetine bağlı melanin kaybı sonucunda PSA'da izlenir1,18. Diğer tip ise, "iğne ucu" benzeri küçük beyaz noktalardır. Fitzpatrick deri tipi 4 ve üzerinde olanlarda düzenli aralıklarla yerleşen ve "bal peteği" görünümüne eşlik edebilen bu noktalar, ekrin ter bezi kanallarının ağızları ya da boş folikül ağızlarını temsil eder. Alopesiye yol açan birçok hastalıkta ve normal saçlı deride görülebilir20.

Kırmızı noktalar: Folikül çevresinde kırmızı renkli halo görülmesiyle karakterizedir. Ortasında kıl ya da keratin tıkaç olabilir. Tosti ve ark. tarafından 2009 yılında 5 DLE'li hastada bildirilmiştir ve DLE için özgül bir bulgu olarak kabul edilmektedir4

\section{Perifoliküler ve interfoliküler bulgular}

Peripilar bulgu: Perifoliküler inflamasyona ikincil gelişen folikül ağzını çevreleyen kahverenkli halodur. Androgenetik alopesi, TE ve normal saçlı deride görülebilir15,21.

Peripilar skuam: Folikül etrafında konsantirik tarzda yerleşir. Frontal fibrozan alopeside (FFA) hafif düzeyde görülebilir. Silindirik tübüler yapıda olanları ise en çok LPP ve FD'de izlenir. Aktif DLE lezyonlarında perifoliküler yerleşimli ince skuamlara sık rastlanır ${ }^{1}$.

Bal peteği pigment ağı görünümü: Saçlı deride görülen pigment ağ yapısıdır. Fitzpatrik deri tipi IV-VI olanların normal saçlı derisinde ve kronik seyirli alopesilerde güneş maruziyetine bağlı olarak saçların seyrek olduğu ya da tamamen döküldüğü kısımlarda görülebilir ${ }^{1}$.

Pembe-beyaz görünüm: Atrofi ve fibrozise ikincil gelişen diffüz pembe-kırmızı ya da sütlü kırmıı renk değişikliğidir ve PSA'lar için özgül bir bulgudur10

Boş foliküller: Folikül içinde saç görülmemesi ile karakterizedir. En sık AGA'da (\%50) görülür. Normal saçı deride de (\%5) görülebilir22,23.

Folikül ağzı yokluğu: Folikül ağızlarının fibrozise bağlı olarak ortadan kalkmasıyla oluşur ve PSA için tanı koydurucudur ${ }^{1}$.

Kir noktaları: Kahve/siyah renkli çevresel kirin saçta görülmesidir. Siyah noktalardan ayırt edimesi gerekir. Tosti ve ark. sadece çocuklarda bildirilmişse de, her yaşta, normal ya da alopesik deride görülebilir7,10.

\section{Damarlar}

Saçlı deride virgül, nokta, firkete, dallanan ve glomerüler gibi çok farklı şekilde kan damarları görülebilir ama saç hastalıklarının pek çoğunda tanı koydurucu bir özellikleri yoktur24.

\section{Normal saçlı deride görülen trikoskopik bulgular}

Normal saçlı derideki terminal kılların kalınlık ve renkleri benzer özelliktedir. Ince saç telleri tüm saçların \%20'sinden azını oluşturur25. Saçlı deride 1-4 adet saç teli içeren foliküler üniteler, boş foliküller, sarı noktalar, küçük beyaz noktalar, bal peteği görünümü, peripilar bulgu, skuamlar ve kir noktaları da görülebilir8,26.

\section{Skar bırakmayan alopesilerde görülen trikoskopik bulgular}

\section{Androgenetik alopesi}

Kıl foliküllerindeki minyatürleşme sonucunda ortaya çıkan saç çapı farklılığının saçların \%20'sinden fazlasında görülmesi AGA için tanı koydurucudur1,15 (Resim 1). Normal saçlı deride \%10'dan az oranda görülen vellüs saçların oranı AGA'da artmıştır8. Ayrıca, sadece bir saç teline sahip foliküler ünitelerin sayısında da belirgin artma vardır. Peripilar bulgu (Resim 1) ve sarı noktalar görülebilir8,10,15. Boş foliküller (Resim 1) ve ileri evrede kronik güneş maruziyetine bağlı olarak bal peteği pigment ağı görünümü de sık rastlanan bir bulgudur ${ }^{1}$ 


\section{Alopesi areata}

Alopesi areatada görülen trikoskopik bulguların başlıcaları düzenli dağılım gösteren incelen saçlar, mikro-ünlem işareti saçlar, sarı noktalar, siyah noktalar, kırık saçlar ve dik ya da yuvarlak şekilde kıvrılmış (domuz kuyruğu) yeni çıkan saçlardır. Trikoskopik bulgular hastalığın aktivitesi, şiddeti ve süresine göre farklılık gösterebilir.

Incelen saçlar (Resim 2A) peribulbar lenfosit inflitrasyonuna bağlı olarak görülür. Inflitrasyona bağlı hasar ne kadar şiddetli ise en hafiften en şiddetliye doğru bükülebilir saçlar, ünlem işareti saçlar, kırık saçlar (Resim $2 \mathrm{~A}$ ve $2 \mathrm{~B}$ ) ve siyah noktalar (Resim 2A) oluşur. Sarı noktalar (Resim 2B) AA için en duyarlı bulgu olsa da AGA, TE, PSA ve normal saçlı deride de görülebilir10. Saçların tekrar çıktığını gösteren bulgular ise dik uzanan kısa vellüsler ve henüz tam iyileşmemiş kıl foliküllerinden çıktığı için kıvrılarak domuz kuyruğu şeklini alan terminal kıllardır14,18.

\section{Telogen effluvium}

Telogen effluviumun özgül trikoskopik bulgusu yoktur. Saç yoğunluğunda azalma, boş foliküller ve sarı noktalar görülebilir1,10,14 Tek saç teline sahip foliküler ünitelerin sayısı artmıştır. Yeni çıkan saçlar sivri uçları, sert ve pigmente gövdeleriyle dikkat çeker11,14. Hastalığın tanısı AGA ve AA incognita dışlanarak konursa da birçok kadın hastada AGA ve TE'un bir arada bulunabileceği unutulmamalıdır.

\section{Anagen effluvium}

Saç tellerinde segmental incelme ve incelen noktalardan kırılmalar görülür. Kırıma en sık deri seviyesinden olur ve siyah noktalar şeklinde görülür. Düşük doz kemoterapi alanlarda kırıma olmaksızın sadece segmental incelme de görülebilir. Çok sayıda incelen bölgenin olması saç teline moniletriks benzeri bir görünüm verir. Ayrıca, boş foliküller sarı noktalar şeklinde izlenebilir18.

\section{Trikotilomani}

Saçların çekilerek koparımasına bağlı olarak ortaya çıkan saç kırıması çok çeşitli trikoskopik bulgular şeklinde görülür. En sık görüleni saçların farklı uzunluklarda kırımasıdır. Kırık saç uçlarında "trikopitilozis" adı verilen kat kat ayrıma (fırçamsı saç) görülebilir. Kırılan saçların distal ucu şiddetli çekmeye bağlı olarak "yuvarlak şekilli" olarak bükülebilir, "soru işaretini" andıracak şekilde kıvrılabilir. Saçlarda diyagonal kırımaya bağı olarak distalleri koyu renkli ve belirgin, ortaları boş "lale saçlar" oluşabilir. Aynı foliküler üniteden çıkan 2 saç telinin aynı noktadan kırılmasıyla da "V-işareti" görünümü oluşabilir. Sarı noktalar, siyah noktalar, mikro-ünlem işareti saçlar ve kısa vellus saçlar trikotilomanide de görülebilir20,27.

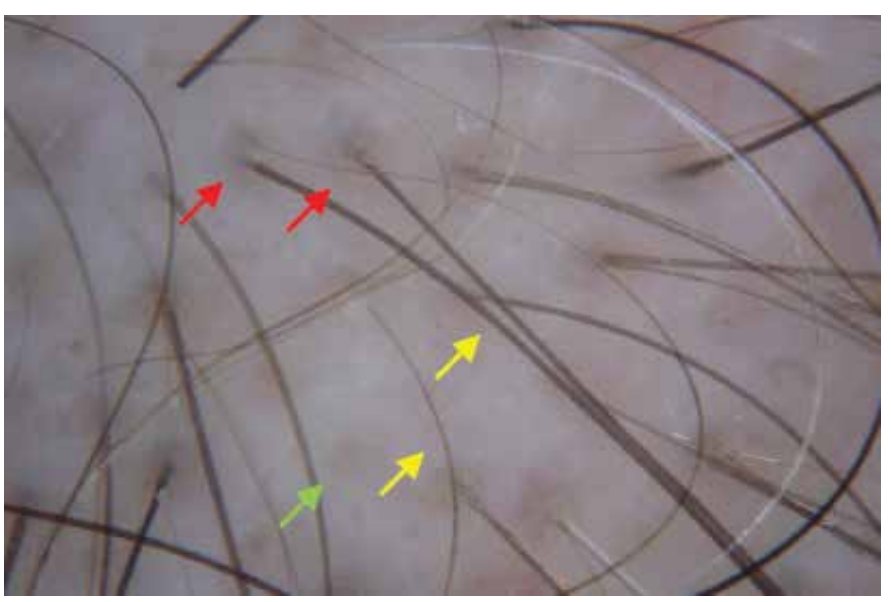

Resim 1. Androgenetik alopeside görülen trikoskopik bulgular. Peripilar bulgu (kırmızı ok), saç çapı farkııığı (sarı ok), boş folikül (yeşil ok) (Orijinal büyütme: $\mathrm{X30}$ )

\section{Traksiyon alopesisi}

Triloskopik bulguları trikotilomaniye benzerlik gösterir. Saç yoğunluğunda azalma, perifoliküler eritem erken bulgularıdır. Kırık saçlar ve lale saçların yanı sıra trikotilomaniden farklı olarak saçı çepeçevre çeviren ince, beyaz renkli keratin silindirleri görülebilir ki, bunlar kıl gövdesi üzerinde serbestçe hareket edebilir. Hastalık kronikleştikçe skatrisyel alopesiye dönüştüğü için bu evrede foliküler açıklıklar kaybolur28.

\section{Skar bırakan alopesilerde görülen trikoskopik bulgular}

\section{Liken planopilaris}

Primer skatrisyel alopesilerin tanı koydurucu bulgusu olan folikül ağzı yokluğu LPP'de de görülür (Resim 3). Hastalığın aktif evresinde peripilar gümüşümsü beyaz renkli skuamlar (Resim 3), interfoliküler yerleşimli skuamlar, trikotilomanideki gibi saçı çepeçevre çeviren ince, beyaz renkli keratin silindirleri görülebilir. Bu silindir şeklindeki kepekler saç telinin dip kısmından ayrılarak yukarı doğru serbestçe hareket edebilir18,29. Aktif hastalık sırasında görülen perifoliküler eritemli halolar inflamasyonu, kronik dönemde ortaya çıkan perifoliküler beyaz halolar ise fibrozisi yansıtır. Zamanla kıl folikülünün ortadan kalkmasıyla beyaz halolar beyaz nokta (Resim 3) halini alıp birbirleriyle birleşir ve sonunda sütlü kırmızı ya da çilekli dondurma renginde fibrotik alanlar
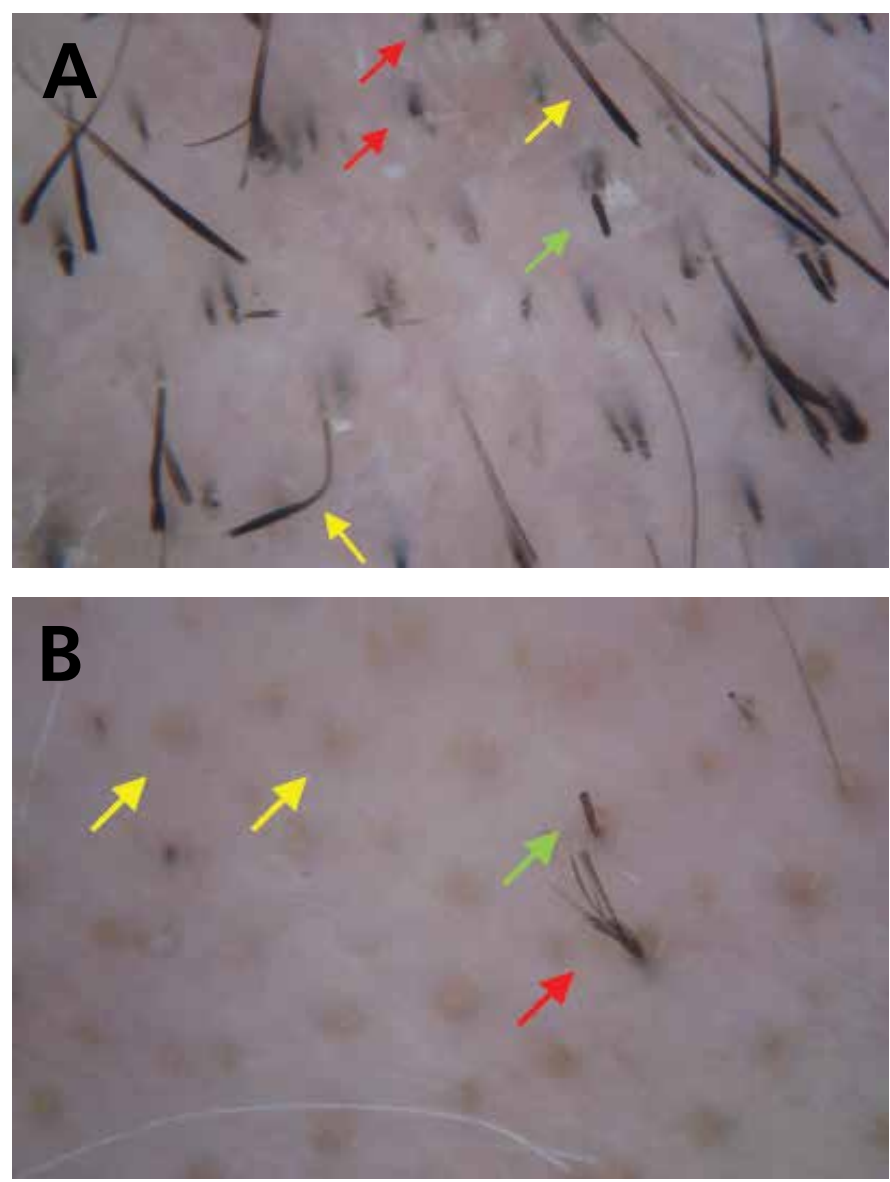

Resim 2. Alopesi areatada görülen trikoskopik bulgular. A, İncelen saçlar (sarı ok), siyah nokta (kırmızı ok), kırık saç (yeşil ok). B, Sarı nokta (sarı ok), distrofik saç (kırmızı ok), kırık saç (yeşil ok). (Orijinal büyütme: $A, B, X 30)$ 
ortaya çıkar. Hastalık daha da ilerleyince bu alanlar solarak fildişibeyaz ya da beyaz renk alır. Olguların $\% 5$ 'inden azında tutam saçlar görülebilir 1,30 .

\section{Frontal fibrozan alopesi}

Liken planopilarisin bir varyantı olarak kabul edilen FFA'da tanı koydurucu trikoskopik bulgu yoktur. Sık görülenler, fildişi-beyaz renkli zeminde folikül ağzı yokluğu ve hafif düzeyde peripilar skuamlardır. Nadiren perifoliküler eritem olabilir. Saçlı deri ya da orijinal saç çizgisi sınırında tek bir terminal kıl içeren ve tek başına duran foliküler açıklıklar görülebilir ki buna "yalnız saç" bulgusu denir. Bu bulgu, nadir de olsa diğer PSA'da da görülebilir 18,31

\section{Diskoid lupus eritematozus}

Aktif evrede keratotik tıkaçlardan oluşan büyük ve koyu renkli sar noktaların görülmesi tipiktir. Bazen bu noktalardan dallanma gösteren ince damarlar çıkar, "sarı noktada kırmızı örümcek" adı verilen bu görünüm fibrozis öncesi inaktif DLE için çok karakteristiktir. Kalın dallanan damarların

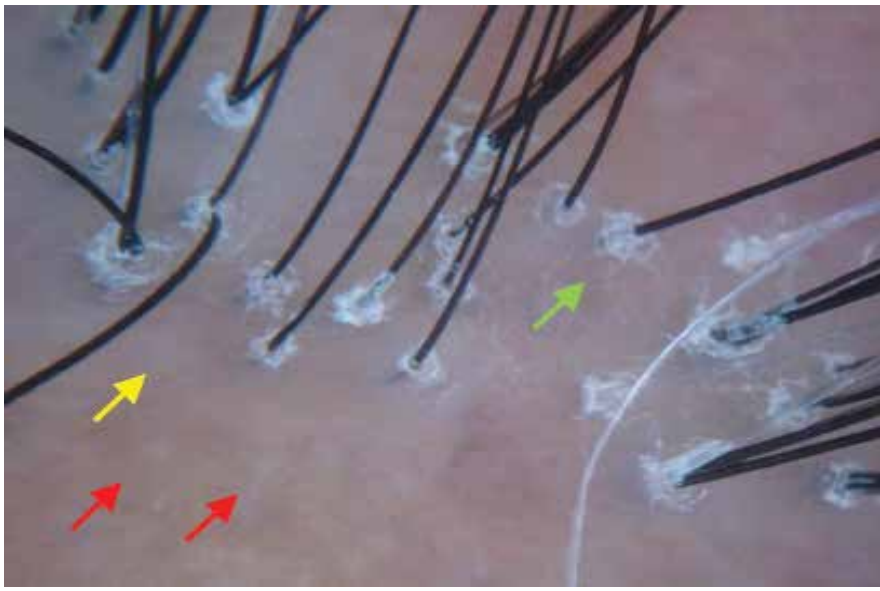

Resim 3. Liken planopilariste görülen trikoskopik bulgular. Folikül ağzı yokluğu (sarı ok), beyaz nokta (kırmızı ok), peripilar skuam (yeşil ok) (Orijinal büyütme: $\mathrm{X30}$ )

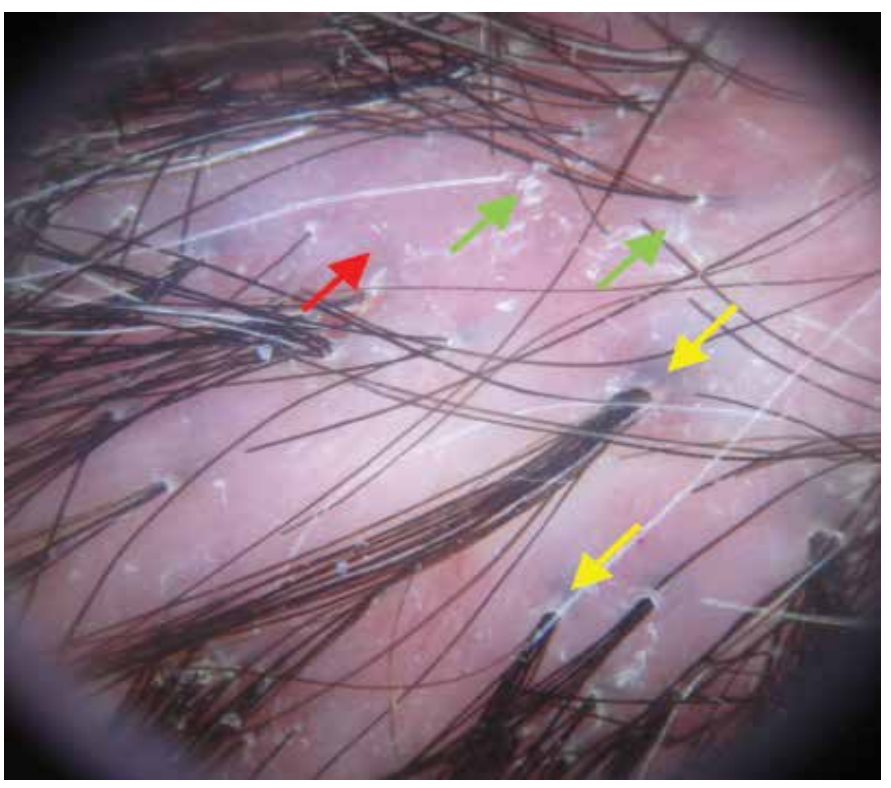

Resim 4. Folikülitis dekalvansta görülen trikoskopik bulgular. Tutam saçlar (sarı ok), sütlü kırmızı görünüm (kırmızı ok), peripilar skuam (yeşil ok). (Orijinal büyütme: X30) görülmesi de sık rastlanan bir bulgudur 18,29. Perifoliküler yerleşimli ince skuamlara da sık rastlanır. Zeminde dağınık şekilde görülebilen ve pigment inkontinansından kaynaklanan koyu kahverenkli renk değişikliği "kirli görünüme" yol açabilir30. Hastaların \%5-\%38'inde görülen foliküler kırmızı noktalar da aktif hastalığın tipik bulgularından biridir. Bunlar folikül ağzı

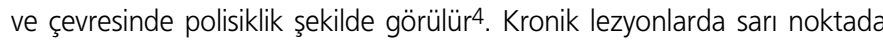
kırmızı örümcek bulgusu dışında sütlü kırmızı veya beyaz zeminde folikül ağzı yokluğu görülür. Diğer PSA'lardan farklı olarak DLE'de fildişi beyaz renk yerine sütlü kırmızı renk dikkat çekicidir. Çok sayıda kalın dallanan damarların görülmesi de DLE lehine yorumlanmalıdır30.

\section{Folikülitis dekalvans}

En sık görülen trikoskopik bulgusu 5'den fazla saç teli içeren "tutam saçlar"dır17 (Resim 4). Tutamların dibinde sarımsı skuamlar ve perifoliküler epidermal hiperplazi bulunabilir ki bunlar kimi zaman "yıldız patlaması" görünümü oluşturabilir29. Sarımsı renkte tübüler skuamlar (Resim 4) ve foliküler püstüller diğer bulgulardır. Kıl gövdesi üzerinde serbestçe hareket eden bu tübüler yapılı keratin silindirleri, LPP'dekinden farklı olarak sarımsı renktedirler ve tutam saçların etrafını çepeçevre sarar. Püstüller başlangıç aşamasında perifoliküler sarımsı renk değişikliği şeklinde görülür, etraflarında uzamış, halka şeklinde kan damarları görülebilir, daha sonra sarımsı renk olan yerde kabarma meydana gelir, damarlanma kaybolur, son aşamada ise koyu kırmız renkli bir alan oluşur. Hastalık ilerledikçe foliküler ağızların kaybolduğu sütlü kırmızı (Resim 4) ya da beyaz renkli atrofik alanlar göze çarpar18,29.

\section{Disekkan sellülit}

En erken aşamada görülen bulgusu büyük perifoliküler püstüllerdir. "Sabun köpüğü" olarak adlandırılan 3 boyutlu sarı noktalar en sık görülen trikoskopi bulgusudur. Bazen orta kısımlarında siyah nokta bulunabilir. Perifoliküler yerleşimli sarı renkli yapısız alanlarda oldukça karakteristiktir. Nadiren siyah noktalar ve etraflarında beyaz halo içeren noktasal damarlar görülebilir. İçlerinde saç tutamları bulunan deri yarıkları da görülebilir. Kronik evrede ise foliküler açıklıkların kaybolur, fildişi-beyaz ya da beyaz renkli bir zemin izlenir ${ }^{18,2}$.

\section{Kaynaklar}

1. Ross EK, Vincenzi C, Tosti A: Videodermoscopy in the evaluation of hair and scalp disorders. J Am Acad Dermatol 2006;55:799-806.

2. Tosti A, Torres F: Dermoscopy in the diagnosis of hair and scalp disorders. Actas Dermosifiliogr 2009;100:114-9.

3. Tosti $A$, Whiting $D$, lorizzo $M$, et al: The role of scalp dermoscopy in the diagnosis of alopecia areata incognita. J Am Acad Dermatol 2008;59:64-7.

4. Tosti A, Torres F, Misciali C, et al: Follicular red dots: a novel dermoscopic pattern observed in scalp discoid lupus erythematosus. Arch Dermatol 2009;145:1406-9.

5. Lacarrubba F, Dall'Oglio F, Rita Nasca M, et al: Videodermatoscopy enhances diagnostic capability in some forms of hair loss. Am J Clin Dermatol 2004;5:205-8

6. Olszewska M, Rudnicka L: Effective treatment of female androgenic alopecia with dutasteride. J Drugs Dermatol 2005;4:637-40.

7. Fu JM, Starace M, Tosti A: A new dermoscopic finding in healthy children. Arch Dermatol 2009;145:596-7.

8. Rakowska A, Slowinska M, Kowalska-Oledzka E, et al: Dermoscopy in female androgenetic alopecia: method standardization and diagnostic criteria. Int J Trichology 2009;1:123-30.

9. Rakowska A: Trichoscopy (hair and scalp videodermoscopy) in the healthy female. Method standardization and norms for measurable parameters. J Dermatol Case Rep 2009;3:14-19.

10. Karadağ Köse Ö, Güleç AT: Clinical evaluation of alopecias using a handheld dermatoscope. J Am Acad Dermatol 2012;67:206-14

11. Inui S, Nakajima T, Itami S: Dry dermoscopy in clinical treatment of alopecia areata. J Dermatol 2007;34:635-9. 
12. Inui S, Nakajima T, Itami S: Significance of dermoscopy in acute diffuse and total alopecia of the female scalp: review of twenty cases. Dermatology 2008;217:333-6.

13. Inui $S$, Nakajima $T$, Shono F, et al: Dermoscopic findings in frontal fibrosing alopecia: report of four cases. Int J Dermatol 2008;47:796-9.

14. Inui S, Nakajima T, Nakagawa K, et al: Clinical significance of dermoscopy in alopecia areata: analysis of 300 cases. Int J Dermatol 2008;47:688-93.

15. Inui S, Nakajima T, Itami S: Scalp dermoscopy of androgenetic alopecia in Asian people. J Dermatol 2009;36:82-5.

16. Tosti A. Alopecia areata. In: Tosti A, editor. Dermoscopy of hair and scalp disorders with clinical and pathological correlations. London (UK): Informa Healthcare; 2007. p. 26-50.

17. Somani N, Bergfeld WF: Cicatricial alopecia: classification and histopathology. Dermatol Ther 2008:21:221-37.

18. Rudnicka L, Olszewska M, Rakowska A, et al: Trichoscopy update 2011. J Dermatol Case Rep 2011;5:82-8.

19. Inui S: Trichoscopy for common hair loss diseases: algorithmic method for diagnosis. J Dermatol 2011;38:71-5.

20. Abraham LS, Pineiro-Maceira J, Duque-Estrada B, et al: Pinpoint white dots in the scalp: dermoscopic and histopathological correlation. J Am Acad Dermatol 2010;63:721-2.

21. Lacarrubba F, Potenza MC, Micali G: Enhanced videodermoscopic visualization of superficial vascular patterns on skin using a 390-to 410-nm light. Arch Dermatol 2012;148:276.
22. Tosti A. Androgenetic alopecia. In: Tosti A, editor. Dermoscopy of hair and scalp disorders with clinical and pathological correlations. London (UK): Informa Healthcare; 2007. p. 15-25.

23. Rebora A, Guarrera M: Kenogen. A new phase of the hair cycle? Dermatology 2002;205:108-10.

24. Rakowska A, Olszewska M, Rudnicka L: Vascular structures in scalp dermoscopy. J Dermatol Case Rep 2013 (in pres)

25. de Lacharrière $\mathrm{O}$, Deloche $\mathrm{C}$, Misciali $\mathrm{C}$, et al: Hair diameter diversity: a clinical sign reflecting the follicle miniaturization. Arch Dermatol 2001;137:641-6.

26. Rakowska A: Trichoscopy (hair and scalp videodermoscopy) in the healthy female. Method Standardization and norms of measurable parameters. $J$ Dermatol Case Rep 2009;3:14-9.

27. Lee DY, Lee JH, Yang JM, Lee ES. The use of dermoscopy for the diagnosis of trichotillomania. J Eur Acad Dermatol Venereol 2009;23:731-2.

28. Inui S, Nakajima T, Itami S: Temporal triangular alopecia: trichoscopic diagnosis. J Dermatol 2012;39:572-4

29. Rakowska A, Slowinska M, Kowalska-Oledzka E, et al: Trichoscopy in cicatricial alopecias. J Drugs Dermatol 2012;11:753-8.

30. Duque-Estrada B, Tamler C, Sodre CT, et al: Dermoscopy patterns of cicatricial alopecia resulting from discoid lupus erythematosus and lichen planopilaris. An Bras Dermatol 2010;85:179-83.

31. Rubegni $\mathrm{P}$, Mandato F, Fimiani M: Frontal fibrosing alopecia: role of dermascopy in differential diagnosis. Case Rep Dermatol 2010;2:40-5. 